\title{
THE SCAPHO-CAPITATE FRACTURE SYNDROME
}

\section{A Mechanism of Injury}

\author{
P. R. W. Monahan and C. S. B. Galasko, Oxford, England \\ From the Accident Service, Radcliffe Infirmary, Oxford
}

The scapho-capitate fracture syndrome associated with perilunar dislocation of the carpus is uncommon. We have found reference to only four cases in the literature (Jones 1955, Van Cauwenberghe 1957, Adler and Shaftan 1962, Stein and Siegel 1969).

There has been some discussion concerning the mechanism of the injury. Stein and Siegel (1969) said that during hyperextension of the wrist the scaphoid bone, which connects

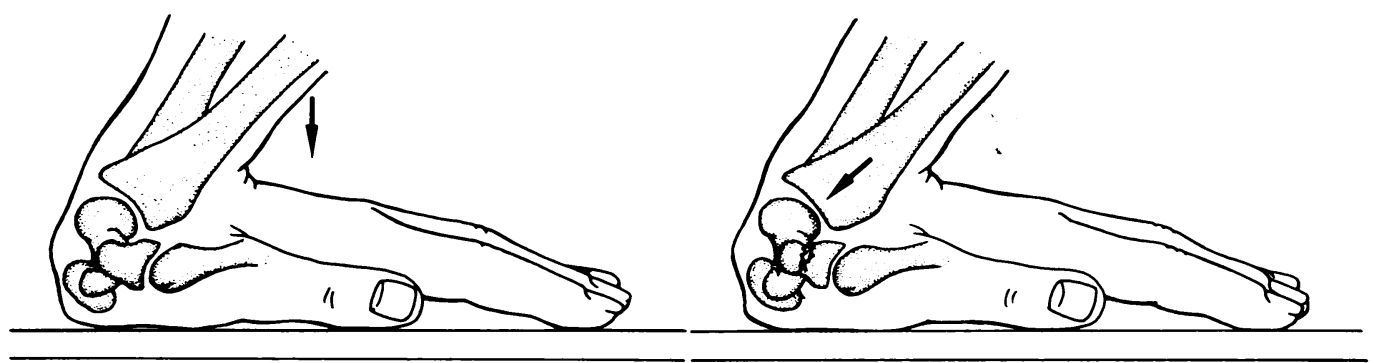

FiG. 1

FIG. 2

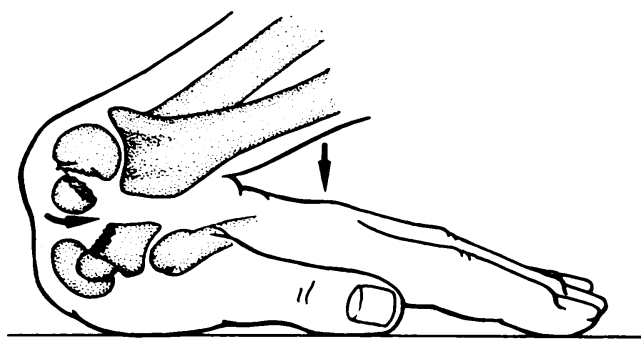

FIG. 3

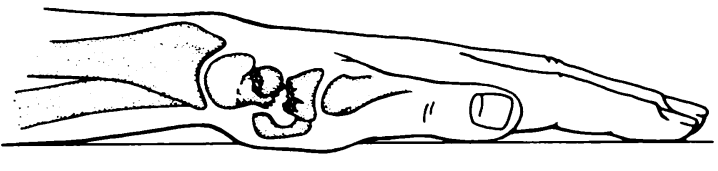

FiG. 4

Modified drawings of the mechanism of injury, from Stein and Siegel (1969).

the proximal and distal rows of the carpus, may be fractured (Fig. 1), and that the lunate bone rotates dorsally on a transverse axis so that its dorsal lip comes to lie under the dorsal edge of the lower radial articular surface. The capitate bone, rotating dorsally with the lunate bone, comes to lie with its long axis perpendicular to the long axis of the radius. A continuation of this hyperextension force causes the dorsal surface of the neck of the capitate to come into contact with the dorsal edge of the lower radial articular surface and to fracture (Fig. 2). If the wrist continues into further hyperextension, the proximal fragment of the capitate is rotated through 90 degrees (Fig. 3). When the wrist returns to the neutral position, the proximal fragment of the capitate assumes a position of 180 degrees rotation in relation to the main fragment of the capitate (Fig. 4).

The axis of this rotation has been discussed by several authors (Fenton 1956, Adler and Shaftan 1962, Stein and Siegel 1969). Stein and Siegel believed that the rotation occurred in the transverse axis. Fenton described two cases of scapho-capitate fracture not associated with perilunar dislocation, in which the proximal fragment of the capitate had rotated through 
180 degrees. He believed that the rotation of the proximal fragment occurred through an axis perpendicular to the palm because the initial displacement of the wrist was one of extension and radial deviation during which the apex of the radial styloid impinged on the lateral surface of the body of the scaphoid bone, causing it to fracture. If the force was great enough, the adjacent capitate bone was fractured at the same level as that of the scaphoid bone and a continuation of the force caused the proximal fragment of the capitate to rotate in a perpendicular plane.

Adler and Shaftan found the axis of rotation to be similar to that recorded by Fenton. Van Cauwenberghe (1957) described a case of the scapho-capitate fracture associated with perilunar dislocation with 180 degrees of rotation of the proximal fragment of the capitate bone, but did not mention the axis of rotation.

The findings in the case to be described support the views of Stein and Siegel regarding the axis of rotation of the capitate fragment.

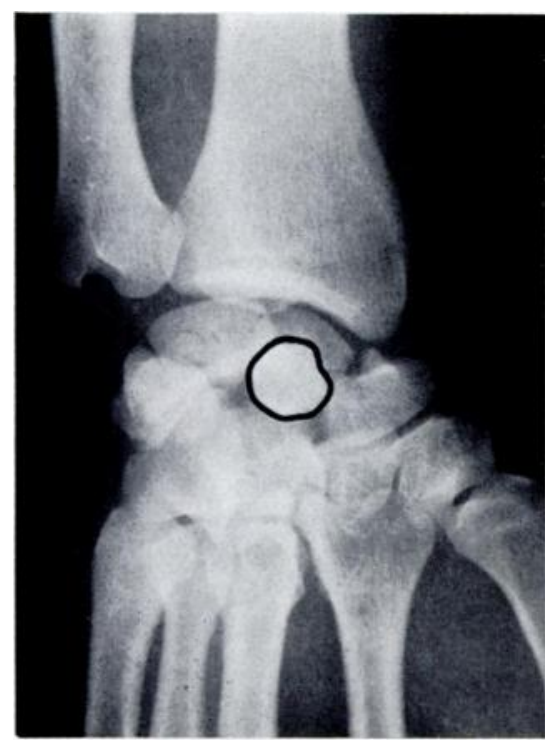

Fig. 5

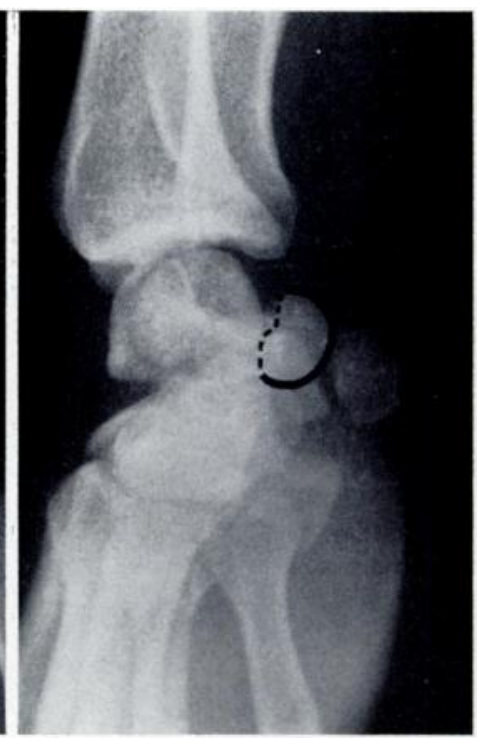

FIG. 6

Antero-posterior and lateral radiographs of the right wrist showing the transscapho-capitate fracture and perilunar dislocation. The proximal capitate fragment (outlined) lies anteriorly with its proximal articular surface towards the palm.

\section{CASE REPORT}

A man aged twenty-four was seen in the Accident Service of the Radcliffe Infirmary in August 1969, having fallen from a height of about 60 feet. He landed first on his left leg and then rolled on to his right side. He sustained a head injury, with traumatic amnesia of about thirty-five minutes, a comminuted fracture of the left calcaneus, and a scapho-capitate fracture with perilunar dislocation of the carpus in which the proximal fragment of the capitate was rotated through 90 degrees (Figs. 5 and 6). The wrist was swollen and he had numbness and paraesthesia affecting the palmar aspect of all the fingers.

Closed manipulation under general anaesthesia failed to reduce the capitate fracture. Therefore open reduction was done through a dorsal incision. The proximal fragment of the capitate bone was found to be displaced anteriorly and rotated so that the articular surface lay anteriorly and the fractured surface dorsally. The interosseous ligament on the ulnar side was intact. With some difficulty the fragment was turned back through 90 degrees and was found to be stable with the wrist held in extension. The fractured scaphoid bone was reduced with the wrist in slight radial deviation. The wrist was immobilised in plaster.

VOL. 54 B, NO. 1, FEBRUARY 1972 


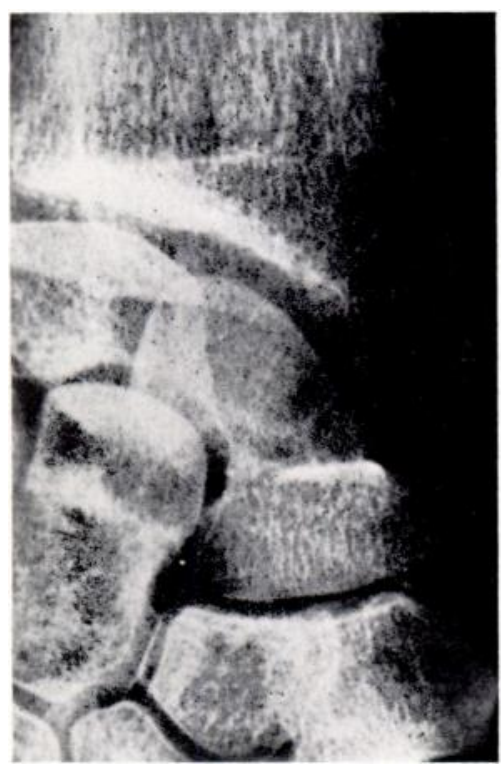

Fig. 7

Radiograph five and a half months after open reduction, showing union of the fractures. There is no evidence of avascular necrosis.
Progress-The wrist was immobilised in plaster for fourteen weeks, by which time there was no tenderness in the anatomical snuff box. Five and a half months from the time of the injury he had no pain over the scaphoid bone. Radiographs (Fig. 7) showed union of both bones with no avascular necrosis of the scaphoid or capitate bones.

\section{DISCUSSION}

In the four cases of the scapho-capitate fracture syndrome that have been reported before, the proximal fragment of the capitate bone had rotated through 180 degrees. It was therefore impossible to determine definitely its axis of rotation, and this may account for the two hypotheses that have previously been advanced (Fenton 1956, Stein and Siegel 1969). In our patient, however, the proximal fragment of the capitate had rotated only through 90 degrees; its position with the proximal articular surface lying anteriorly could only have been achieved by rotating on a transverse axis parallel to the palm. This would confirm the hypothesis of Stein and Siegel.

\section{SUMMARY}

1. A case of the scapho-capitate fracture syndrome is described.

2. At operation the proximal fragment of the capitate bone was found to have rotated on a transverse and not on a vertical axis.

We wish to thank Mr J. C. Scott, Director of the Accident Service of the Radcliffe Infirmary, for permitting us to publish this case and for his helpful advice; to Mr D. R. Floyd for the photographs; Miss J. Palmer (Research Secretary) for her valuable assistance; and Mr F. D. Johnson of Pontefract General Infirmary for the most recent radiographs.

\section{REFERENCES}

Adler, J. B., and Shaftan, G. W. (1962): Fractures of the Capitate. Journal of Bone and Joint Surgery, 44-A, 1537.

Fenton, R. L. (1956): The Naviculo-Capitate Fracture Syndrome. Journal of Bone and Joint Surgery, 38-A, 681. JoNes, G. B. (1955): An Unusual Fracture-Dislocation of the Carpus. Journal of Bone and Joint Surgery, 37-B, 146.

Stein, F., and Siegel, M. W. (1969): Naviculocapitate Fracture Syndrome. Journal of Bone and Joint Surgery, 51-A, 391.

Van Caumenberghe, R. (1957): Un cas rare de fracture-luxation du carpe. Acta Orthopaedica Belgica, $23,79$. 